\title{
Cinética de degradação ruminal de silagens de Brachiaria brizantha com diferentes aditivos microbianos
}

\section{Ruminal degradation kinetic of Brachiaria brizantha silages with different microbial additives}

\author{
Odimári Pricila Pires do Prado ${ }^{1 *}$; Danielle Bandeira Fernandes ${ }^{2}$; \\ Valter Harry Bumbieris Junior ${ }^{1}$; Ivone Yurika Mizubuti ${ }^{1}$; \\ Edson Luis de Azambuja Ribeiro ${ }^{1}$; Fernando Luiz Massaro Junior ${ }^{3}$; \\ Eduardo Lucas Terra Peixoto ${ }^{3}$; Leandro das Dores Ferreira da Silva ${ }^{1}$; \\ Carolina Amália de Souza Dantas Muniz ; Marco Aurélio Alves de Freitas Barbosa ${ }^{1}$
}

\section{Resumo}

Objetivou-se determinar as frações de carboidratos e estimar os parâmetros da cinética de degradação ruminal de Brachiaria brizantha cv. Marandu com a inclusão de dois aditivos microbianos: Aditivo LPPP Pasto (Lactobacillus plantarum e Pediococcus pentosaceus) e Aditivo BSLPPA Pasto (Bacillus subtilis, Lactobacillus plantarum e Pediococcus acidilactici). O delineamento experimental adotado foi o inteiramente casualizado com três diferentes silagens e três repetições por silagem. Os silos foram abertos após 34 dias de fermentação, sendo depois, encaminhadas para análises laboratoriais. Para o fracionamento de carboidratos, foram determinados os carboidratos totais (CHOT), carboidratos nãofibrosos (CNF), as frações A+B1 (frações de rápida e média degradação ruminal), fração B2 (fração lentamente degradada no rúmen) e a fração C (fibra indigerível no rúmen). Os dados da produção de gases foram ajustados ao modelo logístico bicompartimental. Não houve diferença nos valores das variáveis de cinética de degradação dos carboidratos fibrosos e não-fibrosos das silagens analisadas. Porém, silagens de Brachiaria brizantha cv. Marandu ensiladas com os aditivos LPPP e BSLPPA apresentaram maiores frações digestíveis de carboidratos, redução dos carboidratos totais, bem como menor fibra indigestível no fracionamento de carboidratos. Sendo assim, os dois aditivos microbianos melhoraram o valor nutricional da silagem de capim-marandu.

Palavras-chave: Fracionamento de carboidratos, homolático, inoculante bacteriano, ruminantes, taxa de degradação, valor nutricional

\begin{abstract}
This study aimed to determine the carbohydrate fractions and estimate ruminal fermentation kinetics parameters of silages Brachiaria brizantha cv. Marandu with the inclusion of two microbial additives: Additive LPPP Pasture (Lactobacillus plantarum and Pediococcus pentosaceus) and additive BSLPPA Pasture (Bacillus subtilis, Lactobacillus plantarum and Pediococcus acidilactici). The experimental design was completely randomized with three different silages and three replications per silage. The silos were opened after 34 days of fermentation and then sent for laboratory analysis. For the fractionation
\end{abstract}

\footnotetext{
${ }^{1}$ Profs. Drs. do Dept ${ }^{\circ}$ de Zootecnia, Universidade Estadual de Londrina, UEL, Londrina, PR. E-mail: odimari@uel.br;jrbumbieris@ uel.br;mizubuti@uel.br; elar@uel.br; leandro@uel.br; muniz@uel.br

${ }^{2}$ Discente de graduação em Zootecnia, UEL, Londrina, PR. E-mail: danielle.bandeira@hotmail.com

${ }^{3}$ Discentes de Doutorado em Ciência Animal, UEL, Londrina, PR. E-mail: massaro@uel.br; eduzootec@hotmail.com

* Autor para correspondência
} 
of carbohydrates were determined total carbohydrates (TC), non-fiber carbohydrates (NFC), fractions A $+\mathrm{B} 1$ (fractions of fast and average ruminal degradation), B2 fraction (fraction slowly degraded in the rumen) and fraction $\mathrm{C}$ (carbohydrates no digestible in the rumen). The gas production data were fitted to a logistic model bicompartimental. There was no difference in the values of the variables of fiber degradation (FC) kinetic and no-fiber carbohydrates (NFC) of the silages. However, silages Brachiaria brizantha cv. Marandu with use of additives LPPP and BSLPPA had higher fractions of digestible carbohydrates, reducing total carbohydrates and low indigestible fiber fraction of carbohydrates. Thus, the two microbial additives improved the nutritional value of silage Marandu-grass.

Key words: Bacterium inoculant, carbohydrate fractions, degradation rate, homolactic, nutritional value, ruminant

\section{Introdução}

O processo de ensilagem é uma técnica muito utilizada nos sistemas de produção animal, principalmente em pecuária de exploração tecnificada, onde é maior a exigência de volumoso de melhor qualidade. Consiste no processo de conservação em que as forragens úmidas são fermentadas sob condições anaeróbicas, após a compactação das forragens picadas e vedação do silo, tendo como objetivo a preservação do máximo de nutrientes da forragem (SANTOS; ZANINE, 2006).

Como a sazonalidade da produção de gramíneas forrageiras nos trópicos determina elevada produção de massa verde na estação das águas (CASTRO et al., 2006), a produção de silagens de gramíneas como capim-braquiária, vem sendo utilizada como alternativa às culturas tradicionais, pois permite o aproveitamento do excesso de forragem produzida na época das águas para fornecimento aos animais na época seca, quando se evidencia diminuição qualitativa e quantitativa das forrageiras (PEREIRA et al., 2006). Apresenta, ainda, maior flexibilidade na colheita, baixo risco de perda e menor custo por tonelada de matéria seca em relação às culturas de milho e de sorgo (CORRÊA; POTT; CORDEIRO, 2001).

No entanto, as silagens de gramíneas tropicais, inclusive a de capim-braquiária, apresentam algumas características fisico-químicas intrínsecas como, baixos teores de matéria seca, alto poder tampão, reduzido número de bactérias endógenas, e baixo teor de carboidratos solúveis, sendo o principal obstáculo encontrado para o preparo de silagens de gramíneas, pois prejudicam o adequado processo fermentativo (SANTOS; ZANINE, 2006).

Diante dessas limitações, o uso de aditivos microbianos na ensilagem é uma alternativa para melhorar a qualidade da fermentação no silo, pois esses produtos atuam por meio de adição de cepas de bactérias ao processo de ensilagem, com o propósito de manter ao máximo, o valor nutricional da massa ensilada, com produção mais eficiente de ácidos orgânicos (KUNG JUNIOR, 2001). Espera-se também, minimizar as perdas fermentativas por meio da inibição de microrganismos indesejáveis, como leveduras e bactérias do gênero Clostridium (PEDROSO, 2003).

As determinações do valor nutritivo de alimentos a partir de experimentos in vivo, são onerosos e apresentam como desvantagens, o tempo requerido para obtenção de resultados (MAGALHÃES et al., 2006). No entanto, o valor nutritivo pode ser avaliado por meio de experimentos in vitro utilizando-se a técnica semi-automática de produção cumulativa de gases. Esta técnica permite descrever a cinética de fermentação no rúmen e obter a estimativa da taxa de degradação ruminal dos alimentos (BUENO et al., 2005). Ademais, a técnica tem como vantagens a capacidade de avaliar grande número de substratos por experimento, simplicidade no manuseio de equipamento, alta acurácia nas medições e baixo custo na implantação e por amostra analisada (MAURÍCIO et al., 2003). Dessa maneira, a técnica de produção de gases constitui-se em valiosa ferramenta para determinação do valor nutritivo dos alimentos fornecidos aos ruminantes. 
Assim, objetivou-se determinar as frações de carboidratos e estimar os parâmetros da cinética de degradação ruminal de silagens de Brachiaria brizanthacv. Marandu coma inclusão de dois aditivos microbianos: aditivo LPPP Pasto (Lactobacillus plantarum e Pediococcus pentosaceus) e aditivo BSLPPA Pasto (Bacillus subtilis, Lactobacillus plantarum e Pediococcus acidilactici) no processo de ensilagem.

\section{Material e Métodos}

$O$ processo de ensilagem foi conduzido na Fazenda Escola (FAZESC) da Universidade Estadual de Londrina (UEL), localizada no município de Londrina/PR, a $23^{\circ} 23^{\prime}$ de latitude Sul, 51 $11^{\circ}$ de longitude Oeste de Greenwich, e 566 metros de altitude (BARBOSA et al., 2007). O clima local, classificado segundo Köppen, é do tipo Cfa, com precipitação média anual de $1610 \mathrm{~mm}$ e temperatura média anual de $21,1^{\circ} \mathrm{C}$, sendo a média das máximas do mês mais quente de $27,3^{\circ} \mathrm{C}$ e das mínimas do mês mais frio de $16^{\circ} \mathrm{C}$ (IAPAR, 2012).

Neste trabalho foram avaliadas amostras de silagens de capim-marandu (Brachiaria brizantha Stapf cv. Marandu) previamente preparadas. O capim foi cortado para preparo das silagens, após o florescimento, de uma área de pasto já estabelecida com capim-braquiária, sem receber manejos recentes de pastoreio.

A forragem foi ensilada em manilha de concreto não impermeabilizadas com $40 \mathrm{~cm}$ de diâmetro por $100 \mathrm{~cm}$ de altura. Os silos experimentais arranjados três a três, a céu aberto possuíam densidades de compactação de aproximadamente $195 \mathrm{~kg}$ de silagem por $\mathrm{m}^{3}$.

Foram avaliadas três diferentes silagens de capim-marandu (Brachiaria brizantha Stapf cv. Marandu): silagem sem aditivo (controle), silagem com aditivo contendo Lactobacillus plantarum 3,75 x $10^{8} \mathrm{ufc} / \mathrm{kg}$ e Pediococcus pentosaceus de $6,25 \mathrm{x}$ $10^{8} \mathrm{ufc} / \mathrm{kg}$ - denominado aditivo LPPP (4g/tonelada de silagem diluído em água sem cloro) e silagem com aditivo contendo Bacillus subtilis 1,25 x $10^{8}$ $\mathrm{ufc} / \mathrm{kg}$, Lactobacillus plantarum $3,75 \times 10^{8} \mathrm{ufc} /$ $\mathrm{kg}$ e Pediococcus acidilactici 6, $25 \times 10^{8} \mathrm{ufc} / \mathrm{kg}$ denominado aditivo BSLPPA Pasto (4g/tonelada de silagem diluído em água sem cloro). O delineamento experimental foi inteiramente casualizado com três diferentes silagens e três repetições por silagem .

A aplicação do aditivo microbiano foi feita no momento da ensilagem do capim-brachiaria por meio de uma bomba pulverizadora que aspergiu o produto de maneira homogênea no material a ser ensilado a cada $10 \mathrm{~cm}$ de camada compactada, conforme recomendação do fabricante.

Antes da ensilagem, foi coletada uma amostra da forragem fresca para determinação da composição bromatológica (Tabela 1).

Tabela 1. Composição químico-bromatológica, pH, capacidade tampão e nitrogênio amoniacal do capimmarandu antes da ensilagem.

\begin{tabular}{lc}
\hline Parâmetros & $\begin{array}{c}\text { Capim- } \\
\text { marandu }\end{array}$ \\
\hline Matéria seca (\%) & 45,18 \\
Matéria mineral (\% MS) & 8,91 \\
Matéria orgânica (\% MS) & 91,09 \\
Proteína bruta (\% MS) & 5,62 \\
Extrato etéreo (\% MS) & 1,49 \\
Fibra em detergente neutro (\% MS) & 70,58 \\
Fibra em detergente ácido (\% MS) & 39,26 \\
Lignina (\% MS) & 5,96 \\
\hline pH & 5,45 \\
Capacidade Tampão (e.mg HCl/100 g MS) & 14,06 \\
N-amoniacal (\% do N-total) & 2,97 \\
\hline
\end{tabular}

Fonte: Elaboração dos autores.

Os silos foram carregados manualmente, compactados, e vedados com lona de polietileno para impedir a entrada de água no interior dos silos. Após decorridos 34 dias, os silos foram abertos, simultaneamente. De cada manilha foram eliminadas as camadas superiores e as porções laterais evitando materiais deteriorados. 
Foram retiradas três amostras de $1 \mathrm{~kg}$ da camada superficial, média e profunda de cada manilha. Estas foram misturadas e homogeneizadas formando uma amostra composta representativa do total de cada silo. Foram divididas em duas partes. A primeira parte foi embalada em sacos plásticos identificados e congelada. A outra parte das amostras foram colocadas em sacos de papel identificadas, pesadas e levadas para a estufa de ventilação forçada em temperatura de $55^{\circ} \mathrm{C}$ por 72 horas. Após moída em peneira de $1 \mathrm{~mm}$, utilizando-se um moinho tipo Willey, as amostras pré-secas das silagens dos três silos de cada tratamento formaram uma amostra composta final, e colocadas, em recipiente de polietileno identificados para posteriores análises.

As silagens de capim-marandu foram analisadas no Laboratório de Análise de Alimentos e Nutrição Animal do Departamento de Zootecnia da UEL quanto aos teores de matéria seca (MS), matéria mineral (MM), matéria orgânica (MO), proteína bruta (PB), extrato etéreo (EE), lignina (LIG), fibra em detergente neutro (FDN), fibra em detergente ácido (FDA), nitrogênio amoniacal, pH, capacidade tampão, conforme descritos por Mizubuti et al. (2009). As determinações de fibra em detergente neutro corrigido para cinzas e proteína foram realizadas de acordo com Van Soest, Robertson e Lewis (1991).

O fracionamento de carboidratos foi realizado segundo Sniffen et al. (1992), sendo que os carboidratos totais (CT) foram obtidos pela fórmula: $\mathrm{CT}=100-(\mathrm{PB}+\mathrm{EE}+\mathrm{MM})$; e carboidratos nãofibrosos (CNF) estimados pela fórmula: $\mathrm{CNF}=$ $100-(\mathrm{PB}+\mathrm{FDNcp}+\mathrm{EE}+\mathrm{MM})$ em que, FDNcp corresponde ao FDN, corrigido para proteína e cinzas. A fração B2, ou seja, a fração lentamente degradada no rúmen foi determinada pela fórmula: B2= FDNcp - fração C. A fração C, que representa a fração indigestível da parede celular, foi calculada multiplicando-se o percentual de lignina pelo fator 2,4. A fração A + B1, que corresponde às frações de rápida e média degradação ruminal foi determinada pela diferença entre $100-(\mathrm{C}+\mathrm{B} 2)$.

Para obtenção do líquido ruminal, foram utilizados dois bovinos sem raça definida, machos, portadores de cânula ruminal, com idade aproximada de 24 meses, com peso vivo médio de $420 \mathrm{~kg}$, recebendo dieta total à base de silagem de sorgo e aveia, e concentrado contendo milho e farelo de soja, com uma relação volumoso:concentrado de $80: 20$ e ingestão de $1,5 \%$ do peso vivo.

O liquido ruminal foi coletado manualmente através da cânula, antes da alimentação dos animais no período da manhã, filtrado em tecido de algodão com malha fina e colocado em garrafa térmica previamente aquecida a $39^{\circ} \mathrm{C}$ para o transporte até o laboratório. Em seguida, as amostras foram imediatamente incubadas.

Os parâmetros cinéticos de degradação dos carboidratos foram estimados a partir da técnica semiautomática de produção cumulativa de gases in vitro descrita por Schofield, Pitte Pell (1994). Para tal, foram pesados $300 \mathrm{mg}$ de amostra seca ao ar (ASA) moída a $1 \mathrm{~mm}$, e colocadas em frascos de vidros de $50 \mathrm{~mL}$. Todos os frasco receberam $24 \mathrm{~mL}$ de solução tampão de McDougal (1949), previamente reduzida com $\mathrm{CO}_{2}$ até atingir o valor de $\mathrm{pH}$ 6,9. Posteriormente, foram adicionados, em cada frasco, $6 \mathrm{~mL}$ de inóculo oriundo de dois bovinos fistulados no rúmen, sob aspersão de $\mathrm{CO}_{2}$. Para os ajustes de variação, foram incubados frascos sem substrato, considerados brancos para descontar o volume de gases proveniente do líquido ruminal e da solução tampão.

Os frascos de vidro foram vedados hermeticamente com rolha de borracha e imediatamente colocados em câmara BOD, na temperaturas de $39^{\circ} \mathrm{C}$. Foi realizado com auxílio de agulhas a despressurização antes de começar a contagem do tempo de incubação, para certificar que a pressão nos frascos estivesse sob a mesma condição de pressão inicial. A partir deste momento, a pressão dos gases que foram produzidos pela fermentação do substrato e acumulada nos frascos, foi mensurada, por meio de um manômetro modelo MPD-79, de marca Instrutherm, nos tempos de $1,2,3,4,5,6,9,12,18,24,30,36,48,60,72,84$, 96 , e 144 horas. Após cada mensuração foi realizada a despressurização. 
Os valores de pressão expressos em Psi foram convertidos em volume $(\mathrm{mL})$, conforme equação pré-estabelecida para as condições locais: Volume $(\mathrm{mL})=0,5702+3,2399 \mathrm{x}$ Pressão $+0,1074 \mathrm{x}$ Pressão $^{2}\left(R^{2}=0,99\right)$, corrigidos para uma grama de matéria seca, e descontados os valores obtidos nos frascos brancos.

Para a estimação dos parâmetros cinéticos da produção de gases, os dados foram ajustados utilizando-se o modelo logístico bicompartimental (SCHOFIELD; PITT; PELL, 1994), descrito a seguir: $\mathrm{V}=\mathrm{Vcnf} /\left(1+\exp \left(2-4 * \mathrm{Kcnf}^{*}(\mathrm{~T}-\mathrm{L})\right)\right)$ $+\mathrm{Vcf} /\left(1+\exp \left(2-4^{*} \mathrm{Kcf}^{*}(\mathrm{~T}-\mathrm{L})\right)\right)$, em que Vcnf = volume máximo de produção de gases da fração dos carboidratos não fibrosos $(\mathrm{mL}) ; \mathrm{Kdcnf}=$ taxa de degradação dos carboidratos não fibrosos $\left(\mathrm{h}^{-1}\right) ; \mathrm{L}=$ tempo de colonização (h); Vcf = volume máximo de produção de gases da fração dos carboidratos fibrosos (mL.g-1 $)$ Kcf = taxa de digestão para a fração dos carboidratos fibrosos $\left(\% \cdot \mathrm{h}^{-1}\right)$ e Vfinal= volume final de gases produzidos $(\mathrm{mL})$.

Os dados obtidos do fracionamento de carboidrato foram submetidos à análise de variância, e as médias foram comparadas pelo teste Tukey a $5 \%$ de significância utilizando o software estatístico R DEVELOPMENT CORE TEAM (2013).

Posteriormente, os valores dos parâmetros da cinética de degradação ruminal gerados a partir do programa estatístico R (2013), com algorítimo Gauss-Newton, foram submetidos à análise de variância, segundo um delineamento inteiramente casualizado, com cinco repetições. Foi considerado o nível de 5\% de significância.

\section{Resultados e Discussão}

O maior teor de carboidratos totais (CHOT) foi observado na silagem controle seguido da silagem LPPP e silagem BSLPPA $(\mathrm{P}<0,05$; Tabela 2$)$. O menor teor de proteína bruta e extrato etéreo das silagens controle e LPPP $(5,3 \%$ e $1,17 \%$ e $5,88 \%$ e $1,33 \%$, respectivamente), contribuíram para os maiores valores de carboidratos totais. Os valores de CHOT (\%MS) obtidos neste estudo concordam com os relatos de Van Soest (1994), de que estes representam a maior proporção da MS das gramíneas tropicais.

Tabela 2. Fracionamento dos carboidratos e composição bromatológica das silagens de Brachiaria brizantha cv. Marandu com diferentes aditivos microbianos.

\begin{tabular}{lccccc}
\hline & \multicolumn{5}{c}{ Silagens } \\
\cline { 2 - 6 } & Controle & Aditivo LPPP & Aditivo BSLPPA & p-valor & CV(\%) \\
\hline Carboidratos totais (\% MS) & $84,1 \mathrm{a}$ & $82,9 \mathrm{~b}$ & $82,0 \mathrm{c}$ & 0,0001 & 0,43 \\
\hline Carboidratos não fibrosos (\% MS) & 16,1 & 16,2 & 18,1 & 0,1171 & 10,54 \\
A+B1(\% MS) & $32,0 \mathrm{~b}$ & $33,2 \mathrm{~b}$ & $36,1 \mathrm{a}$ & 0,0045 & 5,40 \\
B2 (\% MS) & $45,1 \mathrm{~b}$ & $51,9 \mathrm{a}$ & $48,7 \mathrm{a}$ & 0,0008 & 4,96 \\
C (\% MS) & $22,8 \mathrm{a}$ & $14,8 \mathrm{~b}$ & $15,1 \mathrm{~b}$ & 0,0001 & 11,09 \\
\hline Matéria seca (\%) & 54,9 & 50,0 & 47,7 & & \\
Extrato etéreo (\% MS) & 1,2 & 1,3 & 1,7 & \\
Matéria mineral (\% MS) & 9,4 & 9,8 & 10,2 & & \\
Proté́na bruta (\% MS) & 5,3 & 5,9 & 6,0 & & \\
Fibra em detergente neutro (\% MS) & 73,0 & 71,5 & 69,0 & & \\
Fibra em detergente ácido (\% MS) & 44,5 & 44,8 & 41,0 & & \\
Lignina (\% MS) & 9,5 & 6,2 & 6,3 & & \\
\hline
\end{tabular}

Médias seguidas de letras diferentes na mesma linha diferem pelo teste Tukey $(\mathrm{P}<0,05)$; $\mathrm{A}+\mathrm{B} 1$ : fração solúvel e rapidamente degradável; B2: fração potencialmente degradável; C: fração não degradável. Aditivo LPPP: contendo Lactobacillus plantarum e Pediococcus pentosaceus; Aditivo BSLPPA: contendo Bacillus subtilis, Lactobacillus plantarum e Pediococcus acidilactici; p: Probabilidade; CV: Coeficiente de Variação.

Fonte: Elaboração dos autores. 
Os maiores teores de carboidratos totais é decorrente do estado de maturação da forrageira, pois quanto maior a maturidade da gramínea forrageira, maior a deposição de constituintes da parede celular, principalmente, de lignina, considerada indigestível pelos animais (VAN SOEST, 1994) reduzindo assim, os teores de carboidratos não fibrosos e consequentemente o fornecimento de energia prontamente disponíveis para os microrganismos ruminais.

Não houve diferença entre silagens para os teores de carboidratos não fibrosos (Tabela 2).

Houve efeito $(\mathrm{P}<0,05)$ do aditivo BSLPPA sobre a fração solúvel e rapidamente degradável $(\mathrm{A}+\mathrm{B} 1)$, em que a silagem com aditivo BSLPPA apresentou o maior valor $(36,1 \%)$ em relação às demais silagens, porém, os valores das silagens controle $(33,0 \%)$ e silagem com aditivo LPPP $(33,2 \%)$ não diferiram entre si $(\mathrm{P}>0,05)$. $\mathrm{O}$ aumento percentual observado na fração $\mathrm{A}+\mathrm{B} 1$ da silagem foi em decorrência da redução da fração $\mathrm{C}$ no processo fermentativo, no qual esses carboidratos são incrementados proporcionalmente à redução nos constituintes da parede celular, já que o aumento de um implica na diminuição do outro. Alimentos que contenham elevada fração $\mathrm{A}+\mathrm{B} 1$ são considerados boas fontes de energia podendo aumentar o número de microrganismos ruminais que utilizam CNF. Além disto, pode-se inferir que as silagens com aditivos LPPP e BSLPPA apresentaram melhor valor nutricional do que a silagem controle, do ponto de vista energético, pois possuem maior teor de carboidratos potencialmente digeríveis ( $\mathrm{CNF}$ e fração B2).

Os valores observados neste estudo para carboidratos totais e fração $\mathrm{C}$ foram semelhantes aos encontrados por Bumbieris Junior et al. (2007) que observaram valores de 82,24 a $83,39 \%$, e 18,74 a $19,78 \%$, respectivamente, avaliando silagens de grama estrela (Cynodon nlemfuensis Vanderyst) sem aditivo e com aplicação de aditivo enzimo-bacteriano (150 e $300 \mathrm{~g}$ aditivo/ tonelada de forragem). Entretanto, os valores das frações $\mathrm{A}+\mathrm{B} 1$ e $\mathrm{B} 2$, foram maiores do que as relatadas por Bumbieris Junior et al. (2007) que foram de 24,9 $\%$ CHOT para A+B1 e 55,3\% CHT para B2 em silagens de grama estrela (Cynodon nlemfuensis Vanderyst) sem aditivo.

Houve efeito $(\mathrm{P}<0,05)$ dos aditivos microbianos sobre a fração fibrosa potencialmente degradável (B2). Observaram-se maiores valores para as silagens com aditivos LPPP (51,9\%) e BSLPPA (48,7\%), em relação à silagem controle $(45,1 \%)$. Contudo, os valores das frações B2 das silagens com aditivos LPPP e BSLPPA não diferiram entre si $(\mathrm{P}>0,05)$, mas representaram um aumento de 15,08 e 7,98\%, respectivamente, nas silagens com aditivo LPPP e BSLPPA, comparadas à silagem controle. Esta melhora na fração potencialmente degradável da fração fibrosa pode resultar em aumento no consumo voluntário dos animais, tendo em vista que a baixa degradação da fibra no rúmen ocasiona baixo consumo da dieta (RAVELO, GONZALEZ; DEB HOVELL, 1978).

Os valores da fração $\mathrm{C}$ nas silagens com aditivos LPPP $(14,8 \%)$ e BSLPPA $(15,1 \%)$ também foram menores do que a silagem controle $(22,8 \%)$, mostrando efetividade da ação microbiana sobre o material lignificado do capim-marandu, conforme se pode verificar pelos teores de lignina apresentados nas silagens (Tabela 2). Os aditivos LPPP e BSLPPA promoveram reduções de 34,74 e 33,68\%, respectivamente, nos teores de lignina das silagens, quando comparadas à silagem controle. Portanto, é de grande importância a ação microbiana sobre a fração $C$, pois esta fração dos carboidratos totais é indisponível no rúmen e demais compartimentos do trato digestório, influenciando negativamente o consumo voluntário de alimentos e a disponibilidade de energia (DETMANN, 2010).

Velásquez et al. (2010) avaliaram o valor nutritivo do capim-marandu (Brachiaria brizantha) sem aditivo microbiano, referente ao período de janeiro a março e em três idades de rebrota 
(28, 35 e 42 dias), por meio do fracionamento de carboidratos e observaram valores de 70,56 a $74,18 \%, 19,88$ a $28,21 \%, 53,01$ a $65,33 \%$, para CT, CNF e B2, respectivamente. Valores estes, próximos aos aqui determinados para silagens de Brachiaria brizantha com ou sem o uso de aditivo microbiano (Tabela 2).

As silagens contendo aditivos microbianos apresentaram valores inferiores da fração de carboidrato não degradável $(\mathrm{C})$ em relação à silagem controle $(\mathrm{P}<0,05)$. Isso ocorreu, provavelmente, devido a presença de microrganismos fibrolíticos, tais como o genêro Bacillus que produzem celulases e hemicelulases que promovem a degradação da fibra, produzindo açúcares solúveis utilizados como substrato para fermentação lática, melhorando assim, sua qualidade nutricional. Normalmente, alterações na fração fibrosa da planta forrageira são observadas quando se utiliza aditivos que contém cepas de microrganismos fibroliticos na sua composição (VAN SOEST, 1994).

Bumbieris Junior et al. (2007) avaliando o fracionamento de carboidratos de silagens de grama estrela (Cynodon nlemfuensis Vanderyst.) com aditivo enzimo-bacteriano, observaram que os menores valores para a fração indigestível foram encontrados nas silagens com aplicação de inoculante.

Pode-se observar pela composição bromatológica (Tabela 2) que os teores médios de MS das silagens variaram de $47,72 \%$ a 54,85\%. Esse elevado teor de MS, se deve, provavelmente, ao fato do capim ter sido colhido de uma área de pasto, não recentemente pastejada, de modo que, na colheita do material forrageiro, muita liteira também foi levada ao silo. Os resultados de alto teor de matéria mineral na análise bromatológica das silagens do capimmarandu fortalecem essa hipótese. Os teores de MS encontrados neste trabalho foram superiores aos indicados por Nussio et. al. (2001) que sugeriram valores entre $30 \%$ e $35 \%$ de MS para se obter boas silagens.

O capim-verde e todas as silagens apresentaram teores de PB inferiores ao mínimo de 7\% recomendado por Silva et al. (1999) para o desenvolvimento adequado de bactérias para efetiva fermentação microbiana.

Foram encontrados valores de matéria mineral (MM) variando de 9,42 a 10,25\%, fibra em detergente neutro (FDN), entre 68,99 a 72,95\% e fibra em detergente ácido (FDA) entre 41,01 a $44,75 \%$ na MS. Os valores de extrato etéreo (EE) e Lignina (LIG) variaram de $1,17 \%$ a $1,71 \%$ e de 6,17 a $9,53 \%$ na $\mathrm{MS}$, respectivamente.

Pela cinética fermentativa verificou-se que em silagens contendo menor teor de fibra, principalmente, a silagem com aditivo BSLPPA, houve maior produção de gases em comparação com as demais silagens (Figura 1). Isso pode ser explicado pela pequena contribuição das fibras do alimento na produção total de gases. Segundo Getachew et al. (2004), o montante de gás produzido pelo alimento incubado é devido à produção de ácidos graxos de cadeia curta, que são as principais fonte de energia para ruminantes. A produção de gás ocorre indiretamente a partir da reação entre a solução tampão e os ácidos produzidos na fermentação e degradação microbiana. 
Figura 1. Cinética da produção de gases de silagem de Brachiaria brizantha com aditivo LPPP: contendo Lactobacillus plantarum e Pediococcus pentosaceus; e Aditivo BSLPPA: contendo Bacillus subtilis, Lactobacillus plantarum e Pediococcus acidilactici

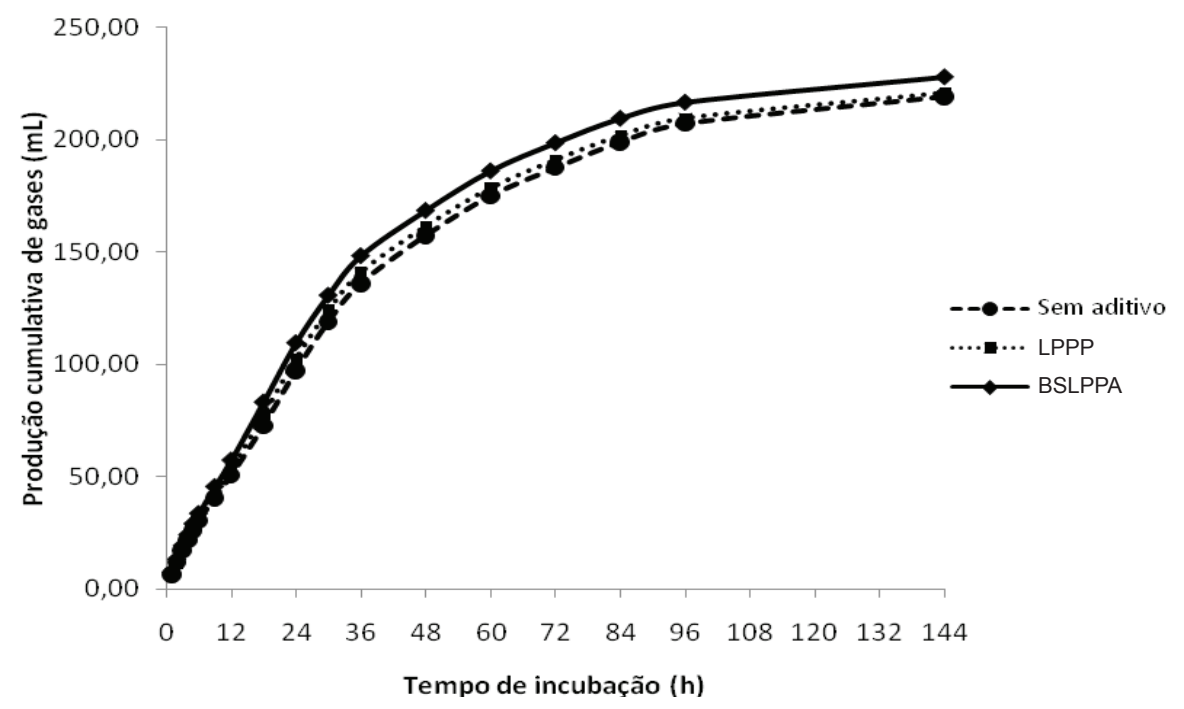

Fonte: Elaboração dos autores.

No tempo de 144 horas de incubação, a silagem com aditivo BSLPPA foi a que apresentou maior volume final de produção cumulativa de gases (227,86 $\mathrm{mL} \mathrm{g-}^{1}$ de MS incubada, P $>0,05$, Tabela $3)$, seguidas pelas silagens com aditivo LPPP $(220,60 \mathrm{~mL})$ e silagem controle $(219,19 \mathrm{~mL})$.

$\mathrm{Na}$ avaliação do volume final de produção de gases das silagens entre os períodos de incubação in vitro; verificou-se aumento significativo na produção cumulativa de gases com o decorrer dos processos de degradação, porém, as produções de gases formados demonstraram tendência de estabilização após 96 horas.

Considerando que o tempo médio de retenção do alimento no rúmen é de 48 horas, quanto maior for a degradação do alimento até 48 horas, melhor é a qualidade fermentativa do alimento (MIZUBUTI el al., 2011). É possível observar na Figura 1 que a silagem controle e silagem com aditivo LPPP foram os que apresentaram menor acúmulo de gases até 48 horas, em termos proporcionais, sendo que 71,81 e $73,16 \%$ do volume final de gases acumulado foi produzido até este tempo para os dois volumosos, respectivamente, enquanto que para a silagem com aditivo BSLPPA, esse percentual foi de $73,91 \%$.

Observou-se que entre as silagens avaliadas não houve diferença $(\mathrm{P}>0,05)$ em relação aos parâmetros cinéticos de produção cumulativa de gases in vitro dos carboidratos fibrosos (CF) e não fibrosos (CNF) (Tabela 3).

Bumbieris Junior et al. (2007) avaliando o efeito do aditivo enzimo-bacteriano sobre a degradabilidade ruminal in situ em silagens de grama estrela, observaram melhora na degradabilidade efetiva da matéria seca e da fibra em detergente neutro nas silagens com aplicação do inoculante. Porém, Schmidt et al. (2007) ao avaliarem a utilização de Lactobacillus buchneri em silagens de cana encontraram ausência de resposta sobre a degradabilidade dos componentes da parede celular com a adição de aditivo bacterianos em relação as silagens controle. Deste modo, os efeitos do uso de aditivos microbianos sobre a degradabilidade em silagens são variáveis. 
Tabela 3. Volume final de produção de gases dos carboidratos não fibrosos (Vcnf) e fibrosos (Vcf) em $\mathrm{mL} \mathrm{g}^{-1}$ de MS, taxa de degradação das frações dos carboidratos não fibrosos (Kdenf) e fibrosos (Kdcf) em mL g-1 de $\mathrm{MS} \mathrm{h}^{-1}$, tempo de colonização em horas (L) e volume final de gases produzidos (Vfinal) das silagens de Brachiaria brizantha $c v$. Marandu com diferentes aditivos microbianos.

\begin{tabular}{|c|c|c|c|c|c|}
\hline \multirow{2}{*}{ Parâmetros } & \multicolumn{3}{|c|}{ Silagens } & \multirow{2}{*}{$\mathrm{CV}(\%)$} & \multirow{2}{*}{ p-valor } \\
\hline & Controle & Aditivo LPPP & Aditivo BSLPPA & & \\
\hline $\operatorname{Vcnf}\left(\mathrm{mL} \mathrm{g}^{-1}\right.$ de MS $)$ & 92,94 & 94,84 & 99,07 & 7,96 & 0,10 \\
\hline $\operatorname{Kdenf}\left(h^{-1}\right)$ & 0,0427 & 0,0459 & 0,0458 & 11,11 & 0,13 \\
\hline $\mathrm{L}(\mathrm{h})$ & 5,649 & 5,587 & 5,033 & 16,37 & 0,11 \\
\hline $\operatorname{Vcf}\left(\mathrm{mL} \mathrm{g}^{-1}\right.$ de MS $)$ & 127,00 & 124,93 & 126,99 & 3,48 & 0,34 \\
\hline $\operatorname{Kdcf}\left(h^{-1}\right)$ & 0,0121 & 0,0124 & 0,0124 & 4,77 & 0,12 \\
\hline Vfinal (mL g-1 de MS) & 220,14 & 218,77 & 225,14 & 3,49 & 0,06 \\
\hline
\end{tabular}

Aditivo LPPP: contendo Lactobacillus plantarum e Pediococcus pentosaceus; Aditivo BSLPPA: contendo Bacillus subtilis, Lactobacillus plantarum e Pediococcus acidilactici; P: Probabilidade; CV: Coeficiente de Variação.

Fonte: Elaboração dos autores.

Sá et al. (2010), avaliando os parâmetros de cinética de degradação ruminal da Brachiaria brizantha cv. Marandu, cortadas aos 28, 35 e 54 dias, pela técnica in vitro de produção de gases , encontraram valores de Vcnf, Vcf, Kdcnf, Kdcf, L e Vfinal, variando entre 68,0 a $116,8 \mathrm{~mL} \mathrm{~g}^{-1}, 68,25 \mathrm{a}$ $83,25 \mathrm{~mL} \mathrm{~g}^{-1}, 0,01$ a $0,05 \mathrm{~h}^{-1}, 0,01$ a $0,02 \mathrm{~h}^{-1}, 12,9$ a $14,6(\mathrm{~h})$ e 160 a $179 \mathrm{~mL} \mathrm{~g}^{-1}$, respectivamente.

O volume de produção de gases dos CNF (Vcnf) da silagem com aditivo BSLPPA foi maior numericamente $(99,07 \mathrm{~mL}, \mathrm{P}=0,10)$ quando comparado com as demais silagens. Altas taxas de produções de gases indicam intensa degradação ruminal da matéria seca, sendo que a fermentação microbiana dos carboidratos produz acetato, propionato e butirato, com consequente formação de metano e gases carbono. A produção de gases que ocorre é proporcional à população microbiana presente e à concentração de fontes de rápida disponibilidade de energia (NOGUERA et al., 2005).

No início do processo fermentativo, que resulta da atividade microbiana, a população de microrganismos presente representa um fator limitador à taxa de produção de gases e, no final, seria a disponibilidade de substrato na amostra.

As silagens com aditivos LPPP e BSLPPA apresentaram maiores taxas de degradação de
CNF (Kdenf) numericamente $(\mathrm{P}=0,13)$, quando comparada a silagem controle, resultando em maiores volumes de produção de gases da fração dos CNF (Vcnf). Este fato pode estar associado ao menor teor de fibra nessas silagens, e portanto, o maior Vcnf é consequência da melhor taxa de degradação de carboidratos não fibrosos.

As silagens de capim-marandu não apresentaram diferença significativa quanto ao tempo de colonização ( $\mathrm{L} ; \mathrm{P}>0,05$; Tabela 3 ). O tempo de colonização ou tempo de latência descreve o tempo decorrido entre o início da incubação in vitro até a ação microbiana sobre as amostras analisadas. Está relacionado com a degradação da fração fibrosa do alimento (MERTENS; LOFTEN, 1980). Observa-se que, numericamente, o maior tempo de colonização foi requerido para silagem controle $(5,6 \mathrm{~h} ; \mathrm{P}>0,05)$ e o menor para a silagem com aditivo BSLPPA (5,03h). O tempo de colonização pode ser reduzido oferecendo aos microrganismos ruminais condições propícias para seu desenvolvimento por meio da presença de substratos rapidamente fermentáveis, ausência de compostos antinutricionais e por características físico-químicas da parede celular da amostra estudada (FARIA et al., 2010).

Quanto ao volume de gases originado pelos carboidratos fibrosos (Vcf) a silagem controle 
e silagem com aditivo BSLPPA geraram numericamente maior produção de gases $(127,0$ e $126,9 \mathrm{~mL}$, respectivamente) em relação à silagem com aditivo LPPP $(124,9 \mathrm{~mL})$, podendo sugerir que estas silagens apresentaram maior fermentação, em função de oferecer condições mais propícias em termos de energia e compostos nitrogenados fornecidos aos microrganismos do que a silagem com aditivo LPPP, possuindo assim maior degradação da fração fibrosa.

As silagens analisadas não apresentaram diferença significativa quanto à taxa de degradação dos carboidratos fibrosos (Kdcf; $\mathrm{P}=0,11$; Tabela 3). A silagem com aditivo BSLPPA apresentou numericamente maior taxa de degradação de CF $\left(0,0125 \mathrm{~h}^{-1}\right)$ em relação às demais silagens. Resultado que pode ser explicado pelo menor teor de FDA (\% MS) facilitando assim, o acesso da microbiota ao substrato. A fração fibrosa de alimentos volumosos que são eficientes na produção de gases são melhores aproveitados e colaboram com a a dinâmica da fermentação microbiana.

Jayme (2008), utilizando-se da técnica in vitro semi-automática de produção de gases para avaliar a cinética de fermentação ruminal de silagens de Brachiaria brizantha sem e com aditivos bacterianos encontraram valores para as variáveis, potencial máximo de produção de gases em $\mathrm{ml} \cdot \mathrm{g}^{-1}$ de MS, tempo de colonização em horas e taxa de produção de gases variando entre 180,98 a 188,98 $\mathrm{ml} \cdot \mathrm{g}^{-1}$ de MS, 4,55 a 4,75 horas e 0,013 a 0,014 $\mathrm{mL} \cdot \mathrm{g}^{-1}$ de MS, respectivamente. Porém, também, chegaram a conclusão que os aditivos microbianos não proporcionaram benefício às silagens analisadas nos parâmetros de cinética de degradação ruminal.

\section{Conclusões}

Apesar dos aditivos microbianos terem aumentado às frações digestíveis de carboidratos e reduzido a fibra indigestível no fracionamento de carboidratos das silagens de Brachiaria brizantha cv. Marandu, não influenciaram os parâmetros de cinética de degradação dos carboidratos fibrosos e não-fibrosos das silagens analisadas pela técnica in vitro de produção de gases.

\section{Agradecimentos}

À empresa BIOCAMPO NUTRIÇÃO ANIMAL pelo fornecimento dos aditivos microbianos para a realização do experimento.

O experimento foi aprovado pelo Comitê de Ética em Experimentação Animal (CEUA/UEL), sob o protocolo $\mathrm{n}^{\mathrm{o}} 17841.2012 .53$.

\section{Referências}

BARBOSA, G. M.C.; TAVARES FILHO, J.; BRITO, O. R.; FONSECA, I. C. B. Efeito residual do lodo de esgoto na produtividade do milho safrinha. Revista Brasileira de Ciência do Solo, Viçosa, v. 31, n. 3, p. 601-605, 2007.

BUENO, I. C. S.; CABRAL FILHO, S. L.; GOBBO, S. P.; LOUVANDINI, H.; VITTI, D. M. S. S.; ABDALLA, A. L. Influence of inoculum source in a gas production method. Animal Feed Science and Technology, Amsterdam, v. 123-124, p. 95-105, 2005.

BUMBIERIS JUNIOR, V. H.; DIAS, F. J.; KAZAMA, R.; ARRUDA, D. S. R.; JOBIM, C. C.; MORAIS, M. G. Degradabilidade ruminal e fracionamento de carboidratos de silagens de grama estrela (Cynodon nlemfuensis Vanderyst.) com diferentes aditivos. Semina: Ciências Agrárias, Londrina, v. 28, n. 4, p. 761-772, out./ dez. 2007.

CASTRO, F. G. F.; NUSSIO, L. G.; HADDAD, C. M.; CAMPOS, F. P.; COELHO, R. M.; MARI, L. J.; TOLEDO, P. A. Características de fermentação e composição químico-bromatológica de silagens de capim-tifton 85 confeccionadas com cinco teores de matéria seca. Revista Brasileira de Zootecnia, Viçosa, v. 35, n. 1, p. 7-20, 2006.

CORRÊA, L. A.; POTT, E. B.; CORDEIRO, C. A. Integração de pastejo e uso de silagem de capim na produção de bovino de corte. In: SIMPÓSIO DE PRODUÇÃO DE GADO DE CORTE, 2., 2001, Viçosa. Anais... Viçosa: UFV, 2001. p. 159-185.

DETMANN, E. Fibra na nutrição de novilhas leiteiras In: PEREIRA, E. S.; PIMENTEL, P. G.; QUEIROZ, A. C.; MIZUBUTI, I. Y. Novilhas leiteiras. Fortaleza: Graphiti Gráfica e Editora Ltda, 2010. cap. 8, p. 253-332. 
FARIA, W. G. J.; GONÇALVES, L. C.; MAURÍCIO, R. M.; RODRIGUES, A. S.; COLODO, J. C. N. ; FARIA, W. G. ; SOUZA, L. F. Avaliação das silagens do sorgo BRS-610 em sete estádios de maturação pela técnica in vitro semiautomática de produção de gases. Arquivo Brasileiro de Medicina Veterinária e Zootecnia, Belo Horizonte, v. 62, n. 4, p. 898-905, 2010.

GETACHEW, G.; ROBINSON, P. H.; DE PETERS, E. J.; TAYLOR, S. J. Relationships between chemical composition, dry matter degradation and in vitro gas production of several ruminant feeds. Animal Feed Science and Technology, Amsterdam, v. 111, n. 1-4, p. 41-56, 2004.

INSTITUTO AGRONÔMICO DO PARANÁ IAPAR IAPAR. Monitoramento agroclimático do Paraná. 2012. Disponível em: <http://www.iapar.br/ arquivos/Image/ monitoramento/ Medias_Historicas/Londrina. htm $>$. Acesso em: 20 maio 2012.

JAYME, C. G. Silagens de Brachiaria brizantha sem aditivo, adicionada de cana de açúcar e aditivos bacterianos. 2008. Tese (Doutorado em Zootecnia) Escola de Veterinária. Universidade Federal de Minas Gerais, Belo Horizonte.

KUNG JUNIOR, L. Silage fermentation and additives. In: SCIENCE AND TEHCNOLOGY IN THE FEED INDUSTRY, 17., 2001, Nottingham. Proceedings... Nottingham: Nottingham University Press, 2001. p. 145159.

MAGAlHÃES, R. T.; GONÇALVES, L. C.; MAURÍCIO, R. M.; RODRIGUES, J. A.; BORGES, I.; RODRIGUES, N. M.; SALIBA, E. O. S.; ARAÚJO V. L. Avaliação de quatro genótipos de sorgo pela técnica "in vitro" semi-automática de produção de gases. Revista Brasileira de Milho e Sorgo, Sete Lagoas, v. 5, n. 1, p. 101-111, 2006.

MAURÍCIO, R. M.; PEREIRA, L. G. R.; GONÇALVES, L. C.; RODRIGUEZ, N. M.; MARTINS, R. G. R.; RODRIGUES, J. A. S. Potencial da técnica in vitro semiautomática de produção de gases para avaliação de silagens de sorgo (Sorghum bicolor (L.) Moench). Revista Brasileira de Zootecnia, Viçosa, v. 32, n. 4, p. 1013-1020, 2003.

McDOUGAL, E. I. Studies on ruminant saliva. 1. The composition and output of sheep's saliva. Biochemical Journal, London, v. 43, n. 1, p. 99-109, 1949.

MERTENS, D. R.; LOFTEN, J. R. The effect of starch on forage fiber digestion kinetics in vitro. Journal of Dairy Science, Savoy, v. 63, n. 9, p. 1437-1446, 1980.

MIZUBUTI, I. Y.; PINTO, A. P.; RAMOS, B. M. O.; PEREIRA, E. S. Métodos laboratoriais de avaliação de alimentos para animais. Londrina: EDUEL, 2009. 228 p.
MIZUBUTI, I. Y; RIBEIRO, E. L. A.; PEREIRA, E. S.; PINTO, A. P.; FRANCO, A. L. C.; SYPERRECK, M. A.; REBOUÇAS, J. R.; CUNHA, G. E.; CAPELARI, G. M.; MUNIZ,E.B. Cinética de fermentação ruminal in vitro de alguns co-produtos gerados na cadeia produtiva do biodiesel pela técnica de produção de gases. Semina: Ciências Agrárias, Londrina, v. 32, p. 2021-2028, 2011. Suplemento 1.

NOGUERA, R. R.; SALIBA, E. O.; GONÇALVES, L. C.; MAURICIO, R. M. Utilização da técnica de produção de gases para determinar a cinética de fermentação dos carboidratos estruturais e não estruturais em sorgo para forragem. Livestock Research for Rural Development, Cali, v. 17, n. 5, 2005. Disponível em: <http://www.lrrd. org/lrrd17/5/nogu17053.htm>. Acesso em: 4 nov. 2013.

NUSSIO, L. G.; CAMPOS, F. P.; DIAS, F. N. Importância da qualidade da porção vegetativa no valor alimentício da silagem de milho. In: SIMPÓSIO SOBRE PRODUÇÃO E UTILIZAÇÃO DE FORRAGENS CONSERVADAS, 2001, Maringá. Anais... Maringá: UEM, 2001. p. 127145 .

PEDROSO, A. F. Aditivos químicos e microbianos como inibidores da produção de etanol em silagens de cana de açúcar (Saccharum officinarum L.). 2003. Tese (Doutorado em Agronomia) - Escola Superior de Agricultura Luiz de Queiroz, Piracicaba.

PEREIRA, O. G.; GOBBI, K. F.; PEREIRA, D. H.; RIBEIRO, K. G. Conservação de forragens como opção para o manejo de pastagens. In: REUNIÃO ANUAL DA SOCIEDADE BRASILEIRA DE ZOOTECNIA, 43., 2006, João Pessoa. Anais... João Pessoa: Sociedade Brasileira de Zootecnia, 2006. p. 507-539.

R DEVELOPMENT CORE TEAM. $R$ : a language and environment for statistical computing. R Foundation for Statistical Computing: Vienna, Austria, 2013. Disponível em: <http://www.R-project.org>. Acesso em: 04 nov. 2013.

RAVELO, G.; GONZALEZ, F.; DEB HOVELL, F. D. The effect of fistula feeding sugar cane or wheat bran on the voluntary intake of sugar cane. Tropical Animal Production, Santo Domingo, v. 3, n. 3, p. 237-242, 1978.

SÁ, J. F.; PEDREIRA, M. S.; SILVA, F. F.; BONOMO, P.; FIGUEIREDO, M. P.; MENEZES, D. R.; ALMEIDA, T. B. Fracionamento de carboidratos e proteínas de gramíneas tropicais cortadas em três idades. Arquivo Brasileiro de Medicina Veterinária e Zootecnia, Belo Horizonte, v. 62, n. 3, p. 667-676, 2010.

SANTOS, E. M.; ZANINE, A. M. Silagens de gramíneas tropicais. Colloquium Agrariae, Presidente Prudente, v. 2, n. 1, p. $32-45,2006$. 
SCHOFIELD, P.; PITT, R. E.; PELL, A. N. Kinetic of fiber digestion from in vitro gas production. Journal of Animal Science, Madison, v. 72, n. 11, p. 2980-2991, 1994.

SILVA, F. F.; GONÇALVES, L. C.; RODRIGUES, J. A. S.; CORRÊA, C. E. S.; RODRIGUEZ, N. M. ; BRITO, A. F.; MOURÃO, G. B. Qualidade das silagens de híbridos de sorgo (Sorghum bicolor (L.) Moench). de portes baixo, médio e alto com diferentes proporções de colmo mais folhas/panícula. I. Avaliação do processo fermentativo. Revista Brasileira de Zootecnia, Viçosa, v. 28, n. 1, p. 21-29, 1999.

SNIFFEN, C. J.; O’CONNOR, J. D.; VAN SOEST, P. J.; FOX, D. G.; RUSSELL, J. B. A net carbohydrate and protein system for evaluating cattle diets: III. Carbohydrate and protein availability. Journal of Animal Science, Madison, v. 70, n. 12, p. 3562-3577, 1992.
VAN SOEST, P. J. Nutritional ecology of the ruminant. 2. ed. Ithaca: Cornell University Press, 1994. 476 p.

VAN SOEST, P. J.; ROBERTSON, J. B.; LEWIS, B. A. Symposium: carboydrate metodology, metabolism, and nutritional implications in dairy cattle. Journal Dairy Science, Champaign, v. 74, n. 10, p. 3583-3597, 1991.

VELÁSQUEZ, P. A. T.; BERCHIELLI, T. T.; REIS, R. A.; RIVERA, A. R.; DIAN, P. H. M.; TEIXEIRA, I. A. M. A. Composição química, fracionamento de carboidratos e proteínas e digestibilidade in vitro de forrageiras tropicais em diferentes idades de corte. Revista Brasileira de Zootecnia, Viçosa, MG, v. 39, n. 6, p. 1206-1213, 2010. 